\title{
Nurses perspective on caring HIV patient
}

\author{
Mohanraj $\mathrm{K} \mathrm{P}^{1^{*}}$, Kamalakannan $\mathrm{K}^{2}$, Arun $\mathrm{K}^{3}$, NoveenaRao. $\mathrm{P}^{4}$ \\ ${ }^{1}$ Professor, Department of Pharmaceutics, Nandha College of Pharmacy, Erode, \\ Tamilnadu, Email:krpmohanraj@gmail.com \\ 2Professor, Department of Pharmaceutical Biotechnology, Nandha College of \\ Pharmacy, Erode, Tamilnadu, Email:car2203@gmail.com \\ ${ }^{3}$ Assistant Professor, Department of Pharmaceutical Chemistry, Nandha College of \\ Pharmacy, Erode, Tamilnadu, Email: arun@nandhapharmacy.org \\ ${ }^{4}$ Associate Professor, Department of Medical Surgical Nursing, Nandha College of \\ Nursing, Erode, Tamilnadu, Email:noveenarao@gmail.com \\ ${ }^{*}$ Corresponding Author
}

\begin{abstract}
Human immunodeficiency virus (HIV) sources cell impairment, which weakens the immune system and marks infections more likely. HIV/AIDS has no known treatment. Antiretroviral Therapy (ART) now available lowers virus multiplication and allows the immune system to be rebuilt. The rehabilitation comprises of three or added distinct medications; the amalgamation is intended to increase efficacy while preventing resistance. Nurses' general responsibilities include, among other things, providing proper information, promoting adherence to therapy, and improving patients' nutritional status.
\end{abstract}

Keywords: HIV, Nurse, Therapy

\section{Introduction}

Acquired immune deficiency condition, also known as AIDS, is triggered by contagion with the human immunodeficiency virus (HIV). AIDS is the maximum progressive juncture of HIV taint. Terminated stretch, the virus targets and kills the body's immune system. Without a completely functional immune system, a person is vulnerable to infections that normally do not harm healthy people. HIV can be passed from one person to another through blood or specific bodily fluids from an infected person to an uninfected person. Mosquitoes, ticks, and other insects do not transmit HIV. It cannot be transmitted through unexpected connection such as talking, shaking hands, hugging, sneezing, sharing dishes, toilets, telephones, or computers, or through water. It is not transmitted via saliva, tears, or perspiration. There are strategies to avoid HIV infection and AIDS because of how HIV is spread.

The majority of HIV infections in the world are transmitted over sex. This suggests that circumventing insecure sex with infested people can prevent the majority of HIV infections. Partaking rummage needles or drug equipment with HIVpositive injectable drug users is the second most common cause of HIV infection. Taking remedy (as a pill every day) is another option to help lower your risk of infection for those who are at high risk of HIV infection, such as injection drug users and people whose partners have HIV. This is known as preexposure prophylaxis, or PrEP.
During pregnancy, birth, or breastfeeding, HIVinfected mothers might spread the infection to their offspring. Treatment of mothers and newborns with anti-HIV medications, C-section delivery, and avoidance of nursing can dramatically lower the incidence of these infections. Since HIV infection habitually has no indications for years, a person might be infected with HIV for a long time and be unaware of it. People frequently feel that if they receive a physical exam, the doctor has tested them for HIV. Most persons who are tested are aware of their status, but there are a few exceptions, such as people entering military service and some people applying for individual health or life insurance plans, who may not be informed.

The most common way for HIV to be discovered is through blood selection tests that seek for anti-HIV antibodies. Additional tests look for antibodies in saliva. When the body becomes infected with HIV, it starts producing antibodies against the virus in an attempt to fight it. Granting these antibodies are not capable of curing HIV, they can be detected in the blood and other physiological fluids within a few weeks of infection. Rather than the virus itself, HIV selection tests look for antibodies. The virus is harder to detect than the antibodies.

A person can be infected with HIV but not have AIDS. AIDS develops once an HIV infection has severely weakened the immune system, a process that can take years. HIV weakens the immune system by dirtying and destroying CD4 cells, a kind of white blood cell. The handling of HIV infection and AIDS is 
complicated, and unexpected diseases can cause staid, even lethal complications. At the moment, the primary HIV treatment consists of three or more antiHIV medications given daily to help prevent the virus from multiplying.

Because HIV is a form of retrovirus, treating it with medications is commonly referred to as anti-retroviral therapy (ART). Highly active anti-retroviral therapy refers to anti-HIV medication combinations that are extremely effective at stopping HIV growth (HAART).

Nurses play an important role in supporting the health and social needs of vulnerable people. The nurse should contribute to the creation of an ethical workplace and speak out against unethical situations or actions. Furthermore, the nurse should contribute to safe and equitable working conditions.

Nurse's part in treating HIV infected patient

The general role of a nurse, according to the ethical code for nurses, is to give care. Other duties include maintaining health and preventing illness and suffering. Respect, trustworthiness, and responsiveness are values associated with nurses. Compassion and integrity should be shown to the sufferers. Patient information should be treated confidentially. Nurses face stress at work as a result of societal stigma and discrimination, which is directed primarily at patients but may also be directed at nurses themselves because they work with HIV/AIDS patients. Sometimes nurses stigmatise HIV/AIDS patients by speaking poorly about them and/or openly discussing them, which reduces the patients' willingness to get tested.

Overcrowding on wards, along with the inability to maintain patient confidentiality, causes stress among nurses. Nurses are often stressed due to a lack of resources, staff, and time. This causes feelings of impotence because they are unable to care for or console the patient to the level that they would like, despite the fact that they observe and acknowledge their patients' pain. Despite the reality that the problem is largely one of a lack of resources and time, society sometimes perceives nurses as not performing their duties successfully. Nurses blame the government for the labour unavailability, stating that they do not receive adequate government support to carry out their duties. Nurses in general show fellow feeling for the HIV/AIDS patients they care for, yet many are frightened of contracting the disease at work. Higher-level educated nurses are less concerned about contagion. A better understanding of HIV/AIDS results in a more favourable attitude toward the patient. Less experienced nurses are more likely to avoid caring for HIV/AIDS patients because they are afraid of transmitting the disease or are insecure due to a lack of knowledge and expertise.

Moral considerations

Suffering is prevalent in wellbeing care settings where patients are critically ill, both for patients and caretakers. Nursing's goal is thus not only to improve health, but also to alleviate woe and assist patients in finding meaning in their misery. The caretakers must have the bravery to address suffering patients and allow room for exist considerations about lifetime and bereavement. Exchange is an important element of the caregiver-patient contact; it could be the sharing of thoughts or experiences. The sharing allows you to empathise with and acquire understanding into the sufferers' predicament. The nurse should be elaborate, existent, and courteous toward the patient.

\section{Empathetic of the HIV patients' condition}

The grouping describes how nurses perceive the patient's position as well as specific topics that the nurses believe are important to the patient. The widely held of nurses saw humiliation as a key issue for patients. According to the nurses, patients who have been diagnosed with HIV face social stigma. According to one nurse, there is less stigma on the unit than in the general public. The intention for the patient's stigma was designated as others considering the patient as not actuality ethically erect and that it was their own culpability that they had constricted HIV, as opposed to if somebody else had contracted HIV. Patients fear being identified as having HIV/AIDS as a result of the stigma, which might lead to a refusal to collect the medication in order to avoid freely revealing that they are infested. At times, the nurses saw patients who had been abandoned by relatives or those close to them. The patients' relatives are expected to care for them during their stay in the ward, ensuring that their hygiene and nutritional needs are addressed. It was uncommon for relatives to forsake the sufferer, although it did occur on occasion. Uncontrolled patients have an sway on nurses' work because there is no one to care after the patients and make sure that they get adequate food or follow their treatment regimen. Because nurses rarely have time to do more than administer the necessary intravenous medications and fluids, they rely significantly on the patient's relatives.

\section{Nurse role in taking care of HIV patient}

Nurses are discovering that their involvement in helpful for HIV/AIDS patients is complex and encompasses a wide range of responsibilities. Many of the nurses had varying perspectives on their roles. Nursing tasks such as soothing patients and providing them affection were highlighted by several of the nurses. The nurses' job in caring for HIV/AIDS patients was also described as reassuring the patient. Counseling patients and family was another nursing responsibility mentioned in the interviews. The nurses provide dietary counselling and disease information to patients and their families, as well as advice on correct treatment. The need of nurses understanding the sickness and the situations of their patients was also emphasised. A problem was highlighted as a deficiency of information midst nurses about how to 
offer ample patient upkeep. More nurses should be taught to care for those living with HIV/AIDS, according to one nurse.

\section{Stress in working environment}

In their regular duties, the nurses were emotionally touched. Several nurses stated that they were stressed and anxious. It was stated that due to a lack of staff, nurses are unable to provide the care they desire, leading to the sensation that they are not doing enough. However, whenever they had the opportunity, they made an effort to be present for the patients. A majority of the nurses were also claimed to be in pain. The fear of catching HIV, as well as the high death rate on the division, were causes that caused nurses to suffer. Pain was viewed as an unavoidable aspect of the health-care profession, which they had to confront and accept. Several difficulties in the workplace were viewed as endangering both patients and nurses. It's possible that there weren't enough gloves to keep hygiene standards up, or that there weren't enough receptacles to put needles in after use, resulting in grievances among the nurses. The patient's reliability may also be jeopardised if they are not appropriately shielded from view by other patients during cleanness dealings on the ward.

A nurse's role is to promote health and alleviate patient suffering. The likelihood of this happening depends on the circumstances. To guarantee that nurses can complete their jobs, it is critical to prevent staff shortages and provide adequate equipment. Spur is also vital in nurses' daily job, which might be enhanced by displaying gratefulness and raising their pay. Advances in the working conditions of nurses, mutually in terms of human wealth and in work milieu, will reduce stress and promote safe practises, benefiting both the nurse and the patient.

\section{Conclusion}

In conclusion, nurses play a difficult task in the care of HIV patients. It is critical that they recognize the various facets of HIV patient situations, not simply the medicinal ones. HIV/AIDS patients frequently experience stigma and poor adherence. The nurse can help to ameliorate this condition by advising and informing patients and their families. Because these people pain can be both somatic and emotional, it is critical for nurses to take a universal methodology in edict to alleviate the patients' anguish. Nurses are also travail as a result of stress and shortages. Efforts must be made to mend the working conditions of nurses in order to improve the situation for both them and the patients. It is also critical to enhance public awareness of HIV in order to reduce stigma. Nurses can help by involvement their knowledge with patients, kinsfolks, and others. Understanding how ARVs operate and the issues our patients experience allows us to better assist them.

\section{References}

1. Delobelle, P., Rawlinson, J.L., Ntuli, S., Malatsi, I., Decock, R. \& Depoorter, A.M. (2009). HIV/AIDS knowledge, attitudes, practices and perceptions of rural nurses in South Africa. Journal of Advanced Nursing. 65(5):1061-1073. doi: 10.1111/j.13652648.2009.04973.x

2. Eide, M., Myhre, M., Lindbaek, M., Sundby, J., Arimi, P., \& Thior, I. (2006). Social consequences of HIVpositive women's participation in prevention of mother-to-child transmission programmes. Patient Education and Counseling. 60(2):146-151.

3. Link, B. G., Struening, E. L., Rahav, M., Phelan, J. C., \& Nuttbrock, L. (1997). On stigma and its consequences: Evidence from a longitudinal study of men with dual diagnoses of mental illness and substance abuse. Journal of Health and Social Behavior, 38:177-190.

4. Lundman, B. \& Graneheim, U.H. (2008). Kvalitativ innehållsanalys. In Granskär, M. \& Höglund- Nielsen, B. (eds.). (2008). Tillämpad kvalitativ forskning inom hälso- och sjukvård (pp. 159-172). (1. ed.) Lund: Studentlitteratur. NHS (National Health Service UK). (2012). HIV and AIDS - Treatment. Retrieved December 3, 2013, from: http://www.nhs.uk/Conditions/HIV/Pages/Treatment pg.aspx.

5. Samuels, J. G., \& Woodward, R. S.( 2015). Opportunities to improve pain management outcomes in total knee replacements: patient-centered care across the continuum. Orthopaedic Nursing 34( 1 ), 4 9 .

6. Sebelius, J.( January 10, 2012). More doctors, hospitals partner to coordinate care for people with Medicare. Available at: https://www.hhs.gov/about/news/ 2013/01/10/more-doctors-hospitals-partnertocoordinate-care-for-people-with-medicare.html

7. Davis, K. , Schoenbaum , S. C. , Gauthier, A. , Nuzum , R. , \& McCarthy , D.( 2008 ). Organizing the U.S. health care delivery system for high performance. New York, NY : The Commonwealth Fund . Retrieved from http://www.commonwealthfund.org/ /media/ files/publications/fund-

report/2008/aug/organizingthe-u-s-health-caredelivery-system-for-high-

performance/shih_organizingushltcaredeliverysys_115 5- pdf

8. Walmart, Lowe's enter bundled pay deal with four health systems. The Daily Briefi ng, October 9, 2013. Available at: https:// www.advisory.com/DailyBriefing/2013/10/09/ Walmart-Lowes-enter-bundledpay-deal-with-fourhealth-systems. The Commonwealth Fund . ( 2015 ). U.S. Healthcare from a global perspective. The Commonwealth Fund Issues Brief. Retrieved from http: //www.commonwealthfund. org/ / media/files/publications/issue-brief/2015/ oct/1819_squires_us_hlt_care_global_perspective_ oecd_intl_brief_v3.pdf 